\title{
Plasmapheresis in steroid-resistant nephrotic syndrome: a case report
}

\author{
K A P P Kanankearachchi ${ }^{1}$, E H K Jayasinghe ${ }^{1}$, A Abeyagunawardana ${ }^{2}$, C D A Goonasekera ${ }^{3}$
}

Sri Lanka Journal of Child Health, 2007; 36: 116-117

(Key words: plasmapheresis, steroid-resistant nephrotic syndrome)

\section{Introduction}

Childhood nephrotic syndrome is common. Causative circulatory plasma factors have been implicated in its pathogenesis, especially after the recognition of rapid and frequent post transplant recurrence of focal segmental glomerular sclerosis (FSGS). As a consequence, therapeutic plasma exchange (TPE) has been added to the treatment armoury of steroid-, cyclophosphamide-, and cyclosporine-resistant nephrotic syndrome, including early post transplant recurrent nephrotic syndrome (FSGS) as a trial therapy. TPE is reported to be successful in inducing complete remission in some patients when instituted early before glomerular sclerotic lesions are advanced ${ }^{1,2}$. Despite definitive evidence of its effectiveness, its role is yet to be determined. We report our first experience of plasma exchange in a child with nephrotic syndrome.

\section{Case report}

An 11 year old boy, of consanguineous parents, with nephrotic syndrome, having undergone 8 months of hospital therapy with intensive immunosuppression without benefit, was referred to our tertiary care unit with oliguria. He was a previously healthy child who first presented with ankle swelling, calf pain and a total serum protein of $46 \mathrm{~g} / \mathrm{l}$, serum albumin of $18 \mathrm{~g} / \mathrm{l}$, and serum creatinine of $0.3 \mathrm{mg} \%$ with non selective proteinuria.

A 6 weeks course of steroids did not induce remission. Serum C3 was $12.75 \mathrm{~g} / 1$ (normal range 5.5-12) and $\mathrm{C} 4$ was $2.9 \mathrm{~g} / 1$ (normal range 2-5). Double stranded DNA, antinuclear antibody and LE cells were negative. Renal biopsy failed. Abdominal scan showed hepatomegaly and thickening of gall bladder wall. Thereafter he had received cyclophosphamide orally, methyl prednisolone (770mg x 3 doses) intravenously followed by pulsed IV cyclophosphamide $(770 \mathrm{mg})$

${ }^{1}$ Temporary lecturer, Department of
Anaesthesiology, ${ }^{2}$ Senior Lecturer, Department of
Paediatrics, ${ }^{3}$ Professor in Anaesthesiology,
Department of Anaesthesiology, Faculty of
Medicine, University of Peradeniya

(Received on 4 October 2006) and later levamisole (80mg every other day) without any benefit. During this period, child also received cryo-poor plasma, spironolactone, frusemide, captopril, nifedipine and hydralazine for symptomatic management of oedema and hypertension and a course of antibiotics for an episode of urinary tract infection. Within 2 months, he was cushingoid and his weight was $57 \mathrm{~kg}$, whereas his hospital admission weight was $25 \mathrm{~kg}$. Further courses of IV methyl prednisolone, ACTH 20 units daily and chlorambucil did not help. Aspirin, vitamins A \& D, calcium carbonate, 1 alpha calciferol, potassium chloride, vitamin $\mathrm{K}$, ranitidine and cyclosporine were added, including co-trimoxazole, daily cryoprecipitate and weekly $20 \%$ human albumin, for symptomatic management.

At the 8th month of his illness, he was oliguric, passing $150 \mathrm{ml}$ of urine per day and became grossly edematous. His haemoglobin was $4.1 \mathrm{~g} / \mathrm{dl}$, blood urea $11 \mathrm{mmol} / 1$ and serum creatinine $232 \mu \mathrm{mol} / 1$. Despite severe anemia, no blood transfusions were given due to the high risk of pulmonary edema. Therefore, continuous therapeutic plasma exchange was performed, replacing 42 litres of plasma volume over 48 hours as a last resort renal rescue strategy. This markedly reduced oedema and the urine output improved from $130 \mathrm{ml} /$ day to 430 $\mathrm{ml} /$ day on the 4th day of plasmapheresis, but the urine protein remained $3+$ to $4+$.

A renal biopsy after plasma exchange revealed mesangial proliferative glomerulonephritis with a focal mesangiocapillary pattern and associated secondary FSGS and global sclerosis. No further treatments were attempted.

\section{Discussion}

Successful treatment of nephrotic syndrome with plasmapheresis in steroid, cyclophosphamide and cyclosporine resistant cases has been reported ${ }^{2}$ especially if initiated early in the course of the disease $^{1}$.

Therapeutic plasma exchange (TPS) is an extracorporeal blood purification technique that removes various molecules in plasma that may be contributing to the pathology $y^{3}$. Most recently, inhibiting substances in serum against permeability maintaining factors have been implicated in 
pathogenesis ${ }^{4}$. Plasmapheresis reduces protein in urine in patients with recurrent FGS by decreasing the capacity of sera to injure the glomerular permeability barrier $^{4,5,6}$. Immunoadsorption of plasma protein also induces remission and restores normal architecture of the foot processes. Experimentally, serum from FSGS increases glomerular albumin permeability whereas plasmapheresis induces remission. Trans-placental transmissions of humoral factors cause transient proteinuria in the child. Some molecular characteristics of such presumed plasma factors have been identified. Recent advances in molecular genetics of FSGS led to the identification of several genes responsible for familial forms. In general, they code for proteins such as NPHS2 of the podocyte and are specifically localized in the glomerular slit-diaphragm where they play a critical role in the control of glomerular permeability ${ }^{6}$.

The frequency and duration of plasmapheresis for FSGS of native kidney and post transplant recurrent disease needs individual tailoring based on clinical response ${ }^{7}$. Some patients experience complete or partial remission of nephrotic syndrome after a certain period of plasma removal but most patients experience relapses 3 to 10 days after the cessation of therapy ${ }^{8}$. Recognized complications of plasma exchange include muscle cramps, hypocalcaemia, hypovolaemia, anaphylactic reactions and urticaria ${ }^{9}$. In the literature, most instances of plasmapheresis were desperate attempts to induce remission. Plasma exchange experience in the treatment of recurrent focal glomerular sclerosis suggests that this procedure is not useful in patients whose allograft biopsy showed advanced glomerular sclerotic lesions ${ }^{10}$. Plasmapheresis is most effective if started soon after the appearance of proteinuria. Remission may result from the removal of plasma permeability factors. On a similar note, it is likely that our child in advanced renal disease was too late to acquire any benefits of plasmapheresis. Therefore, plasmapheresis has to be further evaluated as a therapeutic procedure, especially in the early stages of kidney disease.

\section{References}

1. Laufer J, Ettenger RB, Ho WG, Cohen AH, Marik JL, et al. Plasma exchange for recurrent nephrotic syndrome following renal transplantation. Transplantation 1988; 46: 540-2.
2. Mitwalli AH. Adding plasmapheresis to corticosteroids and alkylating agents: does it benefit patients with focal segmental glomerulosclerosis?. Nephrology Dialysis Transplant 1998; 13: 1524-8.

3. Weber U, Riegel W, Kohler H. Therapeutic plasma exchange 1996. Medizinische Klinik (Munich) 1997; 92: 615-20.

4. Ghiggeri1 GM, Artero M, Carraro M, Perfumo1 F. Permeability plasma factors in nephrotic syndrome: more than one factor, more than one inhibitor. Nephrology Dialysis Transplant 2001; 16: 882-5.

5. Artero ML, Sharma R, Savin VJ, Vincenti F. Plasmapheresis reduces proteinuria and serum capacity to injure glomeruli in patients with recurrent focal glomerulosclerosis. American Journal of Kidney Diseases 1994; 23: 574-81.

6. Ghiggeri GM, Carraro M, Vincenti F. Recurrent focal glomerulosclerosis in the era of genetics of podocyte proteins: theory and therapy. Nephrology Dialysis Transplant 2004: 19: 1036-40.

7. O'Brien CM, McGraw ME, Tizard EJ, Massey E, Saleem MA. Individually tailored plasma exchange treatment for primary and recurrent focal segmental glomerulosclerosis. Archives of Disease in Childhood 2003; 88: A72.

8. Schwarz A. New aspects of the treatment of nephrotic syndrome. Journal of American Society of Nephrology 2001; 12: S44-S47.

9. Mokrzychi MH, Kalpan AA. Therapeutic plasma exchange: complication and management. American Journal of Kidney Diseases 1994; 23: 817-27.

10. Li PK, Lai FM, Leung CB, Lui SF, Wang A, et al. Plasma exchange in the treatment of early recurrent focal glomerulosclerosis after renal transplantation. Report and review. American Journal of Nephrology 1993; 13: 289-92. 